\title{
A comprehensive approach for human hand evaluation of split or large set of fabrics
}

\begin{abstract}
Assessment of fabric handle relies on the feel of humans. The precision of the results greatly depends on the size of fabric sets. It decreases with increasing number of samples as a consequence of assessors' fatigue and loss of concentration. Given the importance of handle assessment and in the absence of guidelines that assist assessment of large sample sets, this study proposes a comprehensive approach for testing large set of fabrics by dividing them in several testing sessions, each of 10 samples at most. In the proposed way, tests can also be split over different panels, even at different locations, provided the panel accuracy is verified beforehand. The method to select the panel members, link the results obtained in different sessions and normalize the data are discussed in this paper. The proposed method was tested on 13 fabrics. Three fabric sensorial attributes (i.e. smoothness, softness and warmth) were assessed in two sessions by a panel consisting of 28 blindfolded members or assessors. Good agreement was found between the panel members for fabric smoothness and softness but the warmth of the fabrics was judged differently as shown by high disagreements between panel members. No significant origin, gender or age-based difference on the judgements were found. The findings of this test study are in agreement with previous studies where well-established assessment methods (i.e., instrumental methods or human panels on smaller dataset) were applied and suggest that the proposed method can be successfully applied to assess large sets of fabrics.
\end{abstract}

\section{Keywords}

Fabric handle, fabric hand, subjective assessment, fabric touch, comfort

\section{Introduction}

Fabric hand or handle is defined in several ways as reported in the literature. Dawes and Owens ${ }^{1}$ referred to it as the sum total of the sensations expressed when a textile fabric is handled by touching, flexing of the fingers, smoothing and so on. The Textile Institute definition goes as 'the subjective assessment the textile material obtained from the sense of touch' ${ }^{2,3}$ while American Association of Chemists and Colorist ${ }^{4}$ defined it as the tactile sensations or impressions which arise when fabrics are touched, squeezed, rubbed or otherwise handled. Ciesielska-Wrobel and Van Langenhove ${ }^{5}$ give a thorough definition of subjective hand of textile i.e. 'The hand of textiles based on the holding of the textile or the smoothing of the textile with the palm is an act of experiencing the textile's thickness and surface, and other textile physical features against the skin of the palm which evokes the impressions related to physical features of the material perceived by the fingers and palm skin receptors and transferred neurologically to the cerebral 
cortex. The judgement is given after referring to the personal experience of the person who makes this judgement as well as his or her natural skin sensibility.' All these definitions address the physical assessment by humans which is referred as subjective assessment or interchangeably termed as human assessment. Studies on this topic was pioneered by Binns ${ }^{6}$ in 1926 and continued until this present time. However, clothing manufacturers may quantify the fabric handle of their products through an in-laboratory method which is using devices such as Kawabata Evaluation Systems for Fabric (KESF) ${ }^{7}$, Fabric Assurance for Simple Testing (FAST), ${ }^{8}$ Fabric Touch Tester (FTT) ${ }^{9,10}$, Material Tactile Tester (MTT) ${ }^{11}$ or using a device that measures only some features on fabric handle such as ring or pulling method ${ }^{5,12-14}$ and Alambeta. ${ }^{15}$ These devices need to objectively measure the fabric properties based on their specified principles and most importantly they should be able to predict the fabric handle of a human. This is schematically depicted in Figure 1. The obtained values from the devices should be correlated with the human touch and thus, predictive models on certain touch attributes can be generated based on the human values through the human assessment. Unlike objective assessment, human assessment is more subjective as the judgement greatly depends on the feel of a human which might be different from one person to another. In order to arrive at qualitative predictive models large sample sets are needed, requiring a comprehensive approach.

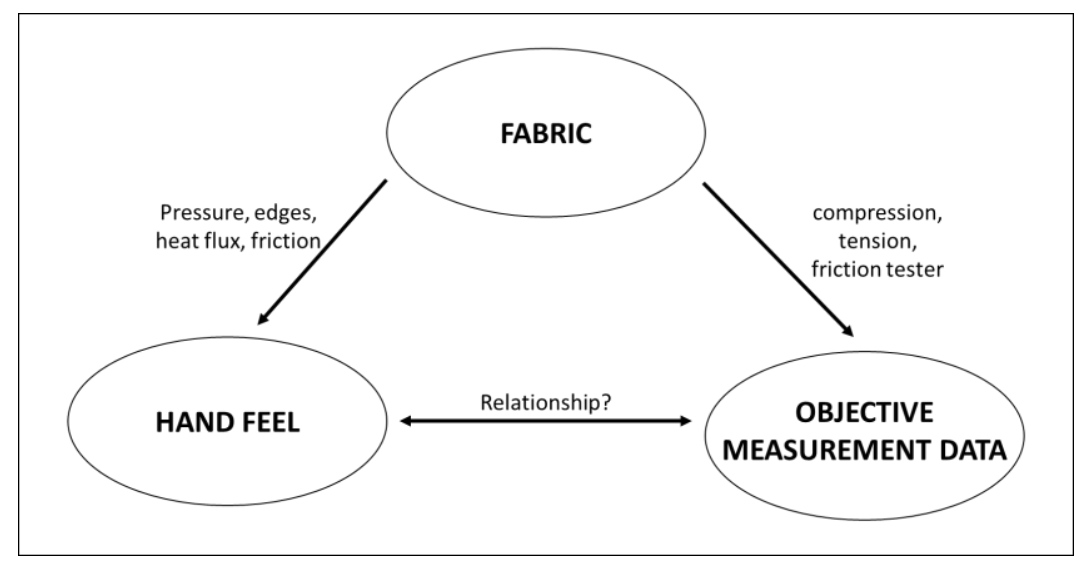

Figure 1 Tactile testing of fabrics via humans or machines, requires establishment of a relation between feel results and machine measurement data.

Although the subjective evaluation by humans are vast and idiosyncratic, to some extent they can agree with each other and some trends can be distinguished. In order to make the assessment results quantifiable, numerical values or scales are assigned to each fabric sensorial attribute which were discussed by Charles et. al. ${ }^{16}$ The assessment involves either ranking, paired-comparison or rating methods ${ }^{2,17,18}$. Ranking is a type of assessment method in which panel members rank or order a set of fabrics according to some selected sensory attributes or descriptors such as warmth, smoothness, crispiness, etc. For instance, in case of 7 fabrics, the smoothness is ranked from score 1 for the smoothest, to score 7 - the least smooth. This method is partly similar to pairedcomparison or also known as pairwise test method, but for the pairwise method, the samples are presented to the panel members in pair (two samples) and comparison on the 
selected fabric attribute is made between the two samples. As the panel members compare only two samples at a time, it is believed that their focus and judgement is better than the ranking method. However, in order to complete the assessment, all the possible combinations of the samples need to be presented to the panel members one after another and after that, the result will be ranked from the most chosen ones until the least. For instance, in case of five fabrics, 10 combinations are possible but larger fabric sets leads to more combinations, following the combination formula $n$ ! / r! (n-r)!, where $n$ is number of samples and $r$ is the chosen samples at one time (i.e. in this case, two samples). The pairwise assessment is impractical as it is time consuming for large sample sets, although the precision among the panel members could be better when compared with the ranking method. Finally, the rating method. For this method, the tested fabric attributes are assessed on a scale e.g. 1 to 10 where normally the two extreme ends or bipolar properties of fabrics are assigned with the lowest (i.e. 1) and highest score (i.e. 10) respectively. A set of fabrics is handed to the panel members who have to identify the extremes or they might be given a reference sample as benchmark and next, assign the scores for other fabrics accordingly. Rating method has an advantage over the ranking method. Based on the given scores, the degree of differences between samples is known whereas ranking method only gives the hierarchy of the samples. However, rating method may lead to a large disagreement amongst the panel members due to unsustain focus in case of large number of samples and previous studies recommended a limitation of number of samples to only 10. ${ }^{19,20}$ This limitation decreases the potential of this method to be practically used for a large sample set, and as 10 is the maximum number of samples, more than 10 should already be considered as a large set. Table 1 summarizes the advantages and disadvantages of each method. To be able to obtain more information from panels members i.e. rank of the samples and degrees of differences between them, and at the same time eliminate the errors due to human factors e.g. unable to sustain the focus for a long time or fatigue, a new approach must resolve these matters. Long testing time and fatigue are known to cause uncomfortable feeling to the assessors, however they have never been taken into account during the assessment.

Table 1 Summary of advantages and disadvantages for methods in human evaluation of fabric handle

\begin{tabular}{|l|l|l|}
\hline Method & Advantages & Disadvantages \\
\hline Ranking & Quick method - time saving & $\begin{array}{l}\text { Not practical for high number of } \\
\text { samples } \\
\text { The degrees of differences } \\
\text { between samples are unknown } \\
\text { Poor way of judgement by panel } \\
\text { members }\end{array}$ \\
\hline $\begin{array}{l}\text { Paired- } \\
\text { comparison }\end{array}$ & $\begin{array}{l}\text { Most accurate way for qualitative } \\
\text { judgement as only two samples } \\
\text { are evaluated at one time. }\end{array}$ & $\begin{array}{l}\text { Very time-consuming } \\
\text { Not practical for high number of } \\
\text { samples }\end{array}$ \\
\hline
\end{tabular}




\begin{tabular}{|l|l|l|}
\hline & & $\begin{array}{l}\text { The degrees of differences } \\
\text { between samples are unknown }\end{array}$ \\
\hline Rating & $\begin{array}{l}\text { The results give more information } \\
- \text { rank of the samples and degrees } \\
\text { of differences between them. }\end{array}$ & $\begin{array}{l}\text { Not practical for high number of } \\
\text { samples }\end{array}$ \\
\hline
\end{tabular}

In addition to the technique used, human evaluation also raises issues such as demographic aspects (i.e. age, gender, origin/ethnicity) of the panel members, blind and non-blind assessment, expert and non-expert assessors, etc. ${ }^{5,17,18}$ In most cases, the AATCC Evaluation Procedure 5-2011 is used which is the only documented guidelines meant specifically for subjective evaluation of fabric handle. ${ }^{4}$ However, these are general guidelines and not specifically tailored to a large set of fabrics. Knowing the potential of the human evaluation as to provide fundamental information especially in generating models for prediction of fabric comfort properties, a method is required to assess a large number of fabrics in wide range, with large pool of panel members from all around the world, testing their own set of fabrics, at their own institutions and to create good statistical predictive models. In the end, these results need to be merged synchronically, which will offer a greater use of the results in the field of tactile comfort.

There are no guidelines at the moment on how disparate tactile experiments can be combined in order to improve the predictive models. There is also an absence of relevant guidelines dealing with large set of samples or split of samples (i.e. geographic or in time). Therefore, this study aims to introduce an improved approach on conducting fabric handle assessment through a blindfolded rating method. For this purpose, three fabric sensory attributes of a non-homogeneous set of 13 fabrics for clothing differentiated among others by fabric construction and raw materials were assessed. The range of fabrics is comparable, in the sense that they are meant to be for apparel clothing. We also propose a selection method of the panel members aiming at eliminating rating discrepancies as results of their origin, age and gender. The approach in this paper is comprehensive as it includes all steps starting from selecting the panel members, sample preparation and handling, experimental and combining rate method procedures, and also analysis, as will be thoroughly explained later. The method allows to increase the datasets required to improve predictive models as it offers the possibility to train models over broader, more disparate (within reason) sample properties such as thickness, construction, mass and others.

\section{Materials}

A non-homogeneous sample set consisting of 13 fabrics was used for the experiments, consisting of cellulosic, wool, polyester and polyamide with woven and knitted structures. The mass per unit area of the fabrics (EN 12127:1997) varied between $122-$ $158 \mathrm{~g} / \mathrm{m}^{2}$ and their thickness from 0.26 to $0.66 \mathrm{~mm}$ (EN ISO 5084:1996). Table 2 shows specifications of the fabrics. The selected fabrics are in the typical range of apparel clothing fabrics. 
Table 2 Specification of the materials

\begin{tabular}{|c|c|c|c|c|c|c|c|}
\hline \multirow[t]{2}{*}{ Fibre composition } & \multirow[t]{2}{*}{ Fabric ID } & \multirow{2}{*}{$\begin{array}{l}\text { Mass per } \\
\text { unit area } \\
(\mathrm{SD}) \\
\mathrm{g} / \mathrm{m}^{2}\end{array}$} & \multicolumn{2}{|c|}{$\begin{array}{l}\text { Yarn linear density } \\
\text { (Tex) }\end{array}$} & \multirow{2}{*}{$\begin{array}{l}\text { Fabric density } \\
\text { (warp/ wale x } \\
\text { weft/ course } \\
\text { per } \mathrm{cm} \text { ) }\end{array}$} & \multirow[t]{2}{*}{$\begin{array}{l}\text { Thickness } \\
\text { (SD), mm }\end{array}$} & \multirow{2}{*}{$\begin{array}{l}\text { Fabric } \\
\text { construction } \\
\text { and finishes }\end{array}$} \\
\hline & & & $\begin{array}{l}\text { Warp/ } \\
\text { wale }\end{array}$ & $\begin{array}{l}\text { Weft/ } \\
\text { course }\end{array}$ & & & \\
\hline $100 \%$ Tencel $^{\circledR}$ & knit-tencel & $125(2.60)$ & $20 / 1$ & $20 / 1$ & $13 \times 16$ & $0.60(0.02)$ & \multirow{5}{*}{$\begin{array}{l}\text { Knitted -Single } \\
\text { jersey } \\
\text { Washed on } \\
\text { frame, no } \\
\text { additional } \\
\text { treatment. }\end{array}$} \\
\hline $\begin{array}{l}50 / 50 \% \\
\text { cotton/Tencel }^{\circledR}\end{array}$ & $\begin{array}{l}\text { knit- } \\
\text { co/tencel }\end{array}$ & $152(0.88)$ & $20 / 1$ & $20 / 1$ & $14 \times 20$ & $0.64(0.02)$ & \\
\hline $100 \%$ Modal $^{\circledR}$ & knit-modal & $140(0.63)$ & $20 / 1$ & $20 / 1$ & $14 \times 20$ & $0.51(0.01)$ & \\
\hline $100 \%$ cotton & knit-co & $157(2.21)$ & $20 / 1$ & $20 / 1$ & $15 \times 20$ & $0.66(0.01)$ & \\
\hline $100 \%$ micro Modal ${ }^{\circledR}$ & knit- $\mu$ modal & $155(1.63)$ & $21 / 1$ & $21 / 1$ & $15 \times 20$ & $0.57(0.02)$ & \\
\hline 100\% micro Modal ${ }^{\circledR}$ & $\begin{array}{l}\text { wov- } \\
\text { umodal }\end{array}$ & $134(0.63)$ & $10 / 1$ & $10 / 1$ & $78 \times 51$ & $0.27(0.00)$ & \multirow{5}{*}{$\begin{array}{l}\text { Woven - Satin } \\
5 / 3 \\
\text { Desized and } \\
\text { washed, no } \\
\text { additional } \\
\text { treatment }\end{array}$} \\
\hline $100 \%$ Tencel $^{\circledR}$ micro & wov- $\mu$ tencel & $136(0.61)$ & $10 / 1$ & $10 / 1$ & $77 \times 51$ & $0.27(0.02)$ & \\
\hline $100 \%$ cotton & wov-co & $135(0.84)$ & $10 / 1$ & $10 / 1$ & $75 \times 58$ & $0.32(0.02)$ & \\
\hline $\begin{array}{l}\text { 100\% Lenzing } \\
\text { Modal }^{\circledR}\end{array}$ & wov-modal & $138(0.46)$ & $10 / 2$ & $10 / 2$ & $78 \times 53$ & $0.27(0.01)$ & \\
\hline $100 \%$ Tencel $^{\circledR}$ & wov-tencel & $131(0.35)$ & $10 / 1$ & $10 / 1$ & $77 \times 52$ & $0.26(0.01)$ & \\
\hline *100\% wool & wov-wool & $122(1.16)$ & $30 / 2$ & $30 / 2$ & $21 \times 18$ & $0.30(0.01)$ & \multirow{3}{*}{$\begin{array}{l}\text { Woven - Plain } \\
\text { weave, } \\
\text { no additional } \\
\text { treatment }\end{array}$} \\
\hline$* 100 \%$ polyester & wov-PET & $132(0.43)$ & $34 / 2$ & $24 / 1$ & $25 \times 20$ & $0.34(0.01)$ & \\
\hline *100\% polyamide & wov-PA & $150(1.62)$ & $44 / 2$ & $22 / 1$ & $22 \times 20$ & $0.43(0.02)$ & \\
\hline
\end{tabular}

*adjacent fabrics used in testing of colour fastness (the specification are controlled according to ISO 105-

F01/F03/F04:2001 standards.

\section{New proposed method for human evaluation of fabric handle}

\section{Selection of panel members}

A human panel consisting of 28 individuals (i.e. textile engineering postgraduate students, researchers or technical staff) was established. The group consists of 14 males and 14 females from age 23 to 56 ( $37 \pm 9$ years). They are from different origins (i.e. 8 from Asia, 5 from Africa and 15 from Europe) but all of them have stayed in Europe for at least one month before the commencement of the assessment. This pool is a mix of members who have experience in assessing fabric hand ${ }^{20}$ and those with no fabric handassessment experience. General guidelines exist for selection, training and monitoring of sensory assessors ${ }^{21}$. In our study, we use a panel of selected assessors where their finger sensitivity was screened with JVP Domes, a kit used to measure spatial acuity of skin surfaces through eight plastic gratings with equidistant bar and grooves widths $(0.35$, $0.50,0.75,1.00,1.20,1.50,2.00$ and $3.00 \mathrm{~mm}){ }^{22}$ This tool is employed to quantify the 
tactile sensitivity of clinical patients who have nervous system disorders or injuries which impaired their touch sensory. ${ }^{23,24}$ The gratings are pressed against the finger of the subject/test person (randomly in any of two orthogonal directions) and the subject has to report the orientation of the grooves and bars to the examiner. The examiner records the answer as correct or incorrect as to be used later in the calculation. This is repeated 20 times and eventually the grating gap and bars width that yield threshold performance of $75 \%$ correct discrimination (that is halfway level between chance and perfect discrimination) is determined.

For this study, the panel members were selected within the range of 0.6 to $1.8 \mathrm{~mm}$ discrimination performance which is calculated based on Equation 1, where $\mathrm{g}$ is the grating spacing, $\mathrm{p}$ is correct trials/number of trials, $g_{\text {high }}$ and $g_{\text {low }}$ refers to the highest and lowest grating spacing on which the patient responded correctly better and lower than $75 \%$ of the time, and $p_{\text {high }}$ and $p_{\text {low }}$ are the probability of correct response on $g_{\text {high }}$ and $g_{\text {low }}$, respectively. $\mathrm{g}_{75}$ is the hypothetical grating spacing on which the panel member would have scored $75 \%$ had it been present. ${ }^{22}$ Based on the range reported in the literatures which is in average of $0.98-1.22$ for normal people,${ }^{2,25-27}$ we considered the range used here (0.6 to $1.8 \mathrm{~mm})$ is satisfactory.

$g_{75}=g_{\text {low }}+\frac{\left(0.75-p_{\text {low }}\right)}{\left(p_{\text {high }}-p_{\text {low }}\right)}\left(g_{\text {high }}-g_{\text {low }}\right)$

(Equation 1)

\section{Sample preparation and handling}

The sample size used for the evaluation is $20 \times 20 \mathrm{~cm}$. The size should be equal for all the samples and should not be less than the mentioned size as that would restrict the movement of the fingers and hand during the assessment. Each panel member received an untouched or untested fabric set, to eliminate the effect of multiple handling that could modify the handle properties of the samples. The fabrics were labelled and left in a controlled room condition at $21^{\circ} \mathrm{C} \pm 2{ }^{\circ} \mathrm{C}$ and relative humidity of $65 \% \pm 4 \%$ for at least 24 hours before the test commenced. ${ }^{28}$

On the assessment day, the samples to be tested were placed on an equal non-metallic table (low thermal absorption) with the surface to be evaluated facing up. As the position of the samples needs to be reshuffled during the assessment, it is advisable to place the samples inside of moveable cardboard blocks so that the process can be done at ease without touching the samples. The blocks with the samples were placed randomly next to each other. Flat A4 printing papers are placed in between the sample and the cardboard, to avoid any cardboard texture influence, which may occur especially in the case of thin fabrics. The samples, the cardboard with papers of $2 \mathrm{~mm}$ thick, and also the table started at an equal temperature as the test was conducted in a controlled climate room.

During the assessment, especially in case of large number of fabrics, the panel members will need to make some moves in order to reach the samples situated out of their arm length. Hence, it is also important to consider the ergonomic aspect of the table on which 
the samples are placed, especially its length and height to avoid any uncomfortable position to the panel members during assessment.

\section{The blind rating method experimental procedure}

Tactile feel is a multidimensional concept which involved several attributes including compression, friction, surface roughness, dynamic thermal contact property etc. ${ }^{29}$ In this study, three fabric sensory attributes or descriptors were to be assessed i.e. smoothness, softness and warmth. These three attributes are often used to explain the judgements made on fabric handle ${ }^{9,30}$ and also included in ASTM D123 standards on terminology used to describe hand. ${ }^{31}$ Smoothness refers to a surface free from projections, irregularities or inequalities ${ }^{32}$. The opposite property of smoothness is roughness which is described by the indentations and ridges on the fabric surface ${ }^{33}$. Softness relates to the ability of the fabric to bend as fabrics that can easily bent are described as soft and the opposite property is stiff or hard. However, other than bending, properties such as compressibility and shearing rigidity are also related in the assessment of softness ${ }^{3}$. The perceived warmth or coolness of a surface is a measurement of how fast or slow heat is conducted out of the $\operatorname{skin}^{34}$ and it is the first fabric-skin contact feeling of heat exchange.

A number of 13 fabrics was used for this experiment and the details of the fabrics were described in the previous section. As several researchers suggested to limit the maximum numbers of samples tested in one session to 10 samples, a sample set larger than 10 samples could be then considered a large sample set. Our new approach complements previous research dealing with more than 10 samples and proposes a more practical approach to handle the samples.

Rating method with some improved steps was employed for evaluation as it provides more information about the samples and as it is the only way to combine results of multiple sessions as we show later. A scale from 1-10 was used where 1 and 10 were assigned for the extreme opposites of the attributes. For instance, score 1 is assigned to the roughest, stiffest and coolest sample and score 10 indicates the smoothest, softest and warmest sample, respectively. The assessment was conducted in laboratory environment with controlled temperature and humidity $\left(20 \pm 2^{\circ} \mathrm{C}, \mathrm{RH} 65 \pm 4 \%\right)^{28}$ and was supervised by a test facilitator. For each fabric attribute, the panel members used their dominant hand to touch the samples ${ }^{33}$. The procedures were explained by the facilitator (see Table 3 ) to guide the panel member to get the intended feeling for the specified attributes. The fabric can be grasped in many different ways, depending on the testing person as reported by other researchers ${ }^{35,36}$. However, we ask the assessors to use the same touch method as specified in Table 3 so as to gain the feel from the same gesture from all of them.

Table 3 Touch methods and description for fabric touch evaluation

\begin{tabular}{l|l}
$\begin{array}{l}\text { Fabric attribute } \\
\text { to assess }\end{array}$ & Touch method \\
\hline
\end{tabular}




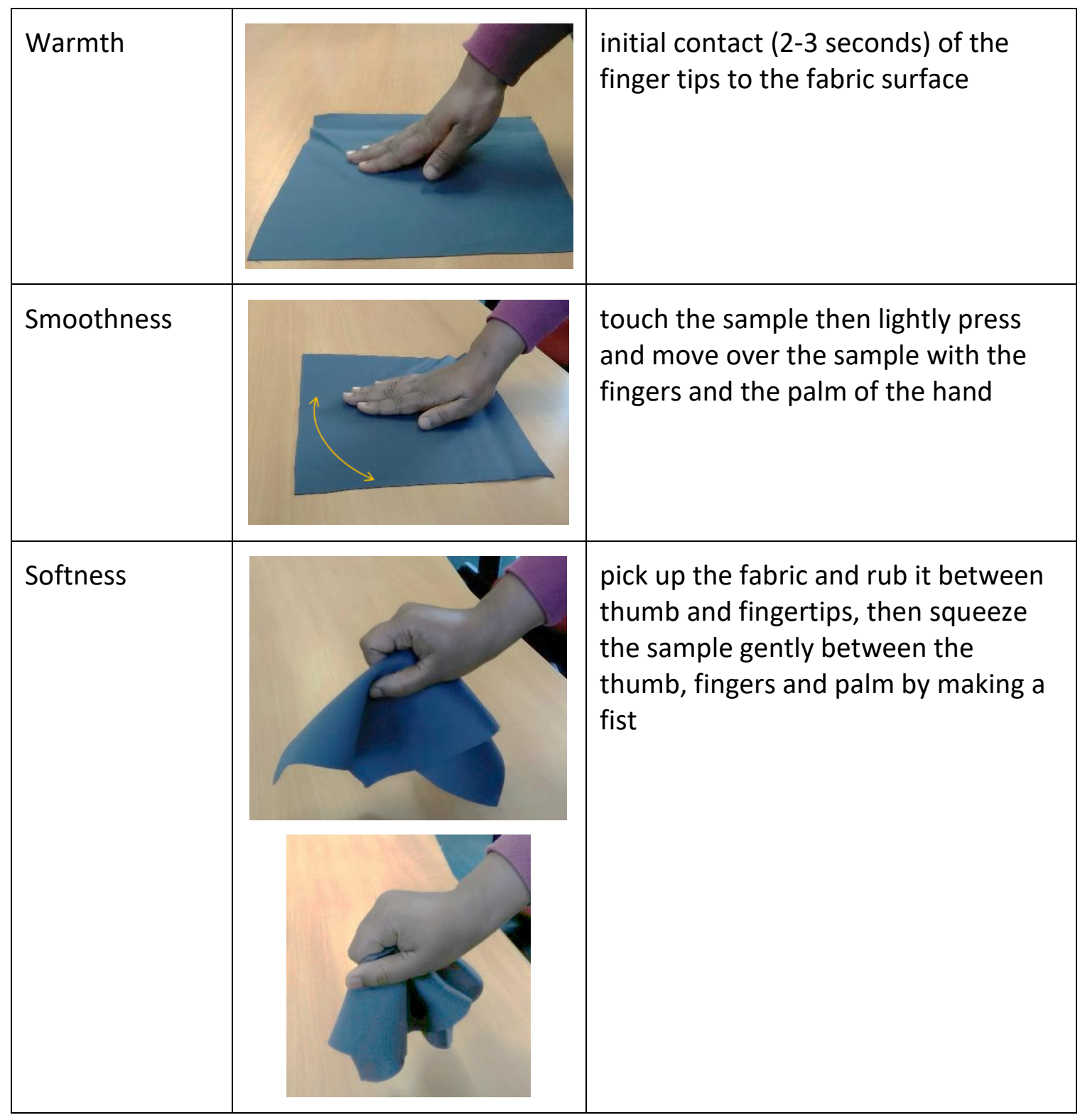

Prior the assessment day, the procedures were disseminated to the panel members. They were also reminded not to put any moisturizing cream or lotion onto their hands on the assessment day as that might affect the touch perception during the assessment. When they enter the room, first they were asked to wash their hands with a standard soap, and dry them with the provided towels ${ }^{33,37}$. Next, they were allowed to acclimatize for about 15 minutes in the room and asked to minimize the use of their hands. During this period, the test facilitator briefed the assessment procedures and the methods to the panel to ensure that the test will run smoothly. To avoid the visual influence during assessment, a blindfold was placed onto the assessor's eyes.

As suggested by AATCC 5-2011 procedure, thermal related attributes should be the first to assess prior to other attributes, hence warmth was assessed first ${ }^{4}$. While the eyes were blindfolded, the panels first identified the extreme samples i.e. coolest and warmest, thus 
assigned them score 1 and 10 respectively. After that, they were asked to rate the rest of the samples using the given scale of $1-10$ by comparing them with the extremes they picked earlier. Since the panel members were blindfolded, they might have difficulties to write the rating on their own, hence they may communicate with the test facilitator who will then record it on the assessment sheet on their behalf. To maintain the random position of the samples, they were rearranged before the assessment of the next attribute, this is done with the help of an available online mobile application to shuffle the sample list as to avoid any human bias. Then, assessment of smoothness and softness took place with the same procedures as in warmth. Three-minutes interval was taken in between the assessment of two consecutive fabric attributes. The panel members were allowed to rest and they could put off the blindfold during that time. It is important to make sure that they turn to the other direction as not to see the samples in order to avoid visual bias in the results.

\section{Combining rate method results}

There is a concern reported by previous researchers when using a high number of samples for human assessment as that has created more disagreement on the results amongst panel members. ${ }^{19,20}$ This might be associated with fatigue or lack of focus in dealing with the samples thus the panel were unable to perceptually recognize each of them. Hence, it was recommended to limit the number of samples tested in one session to 10 samples. ${ }^{19,20}$ This limitation impedes the potential of this type of assessment in giving meaningful results. Therefore, in addition to the available protocols, we improve to make them also suitable and useful for split testing (geographical or in time) as well as generally for large number of samples, i.e. more than 10 samples. Thus, the samples are split into several batches (each of maximum 10 samples) and then the test for the first batch is run. After that, for each attribute, two samples are chosen as the best and worst, hereafter called reference samples. These samples are added to the second batch of samples and then the test is run again in the second session. For the consequent batches, the same method is applied until the assessment of all batches is finished. Figure 2 shows an example of how 26 samples (A to $\mathrm{Z}$ ) are divided into three batches to be tested in three sessions. For batch one, 10 sample from A to J are included. During the first evaluation session, the smoothness of the samples is assessed and sample $\mathrm{A}$ and $\mathrm{J}$ are chosen as the extremes or references i.e. the smoothest and roughest, respectively. In the second session, ten samples are tested, which includes these two sample together with eight other samples, i.e. K to R. So only 8 new samples are added, for a total of 18 after two sessions. From the second session, suppose that samples A and Q are selected as the reference by the panel members, hence these two will be included in the third batch of samples together with again eight new other samples i.e. $\mathrm{S}$ to $\mathrm{Z}$, and tested in session three for a cumulative amount of 26 samples. Note that in this example, sample $A$ is tested in every session as it is picked as reference in each session. Although it is assessed in three sessions, it is a good practice to always use a fresh sample for each session in order to avoid any fabric changes as results of previous touch sessions. Through this suggested blind rate method, the focus of the panels can be sustained as only a limited number of samples is used, thus eliminating the chances for uncertain judgements influenced by the human factors as mentioned before. 
In this study, we have applied this method to 13 fabrics and the assessment was split in two sessions. In the first session, a batch of seven samples was tested namely knitted Tencel $^{\circledR}$, cotton and $\mu$ Modal $^{\circledR}$; woven $-\mu$ Modal $^{\circledR}$, cotton, Modal ${ }^{\circledR}$ and Tencel ${ }^{\circledR}$. During the second session the six remaining fabrics i.e. knitted - cotton/Tencel ${ }^{\circledR}$ and Modal ${ }^{\circledR}$, woven $-\mu$ Tencel $^{\circledR}$, wool, polyester and polyamide were tested together with the two reference samples from the first session. There was a gap of one week in between the assessment of the first and the second batch. Later in the analysis, all the samples of the different sessions can be combined as given in the next section.

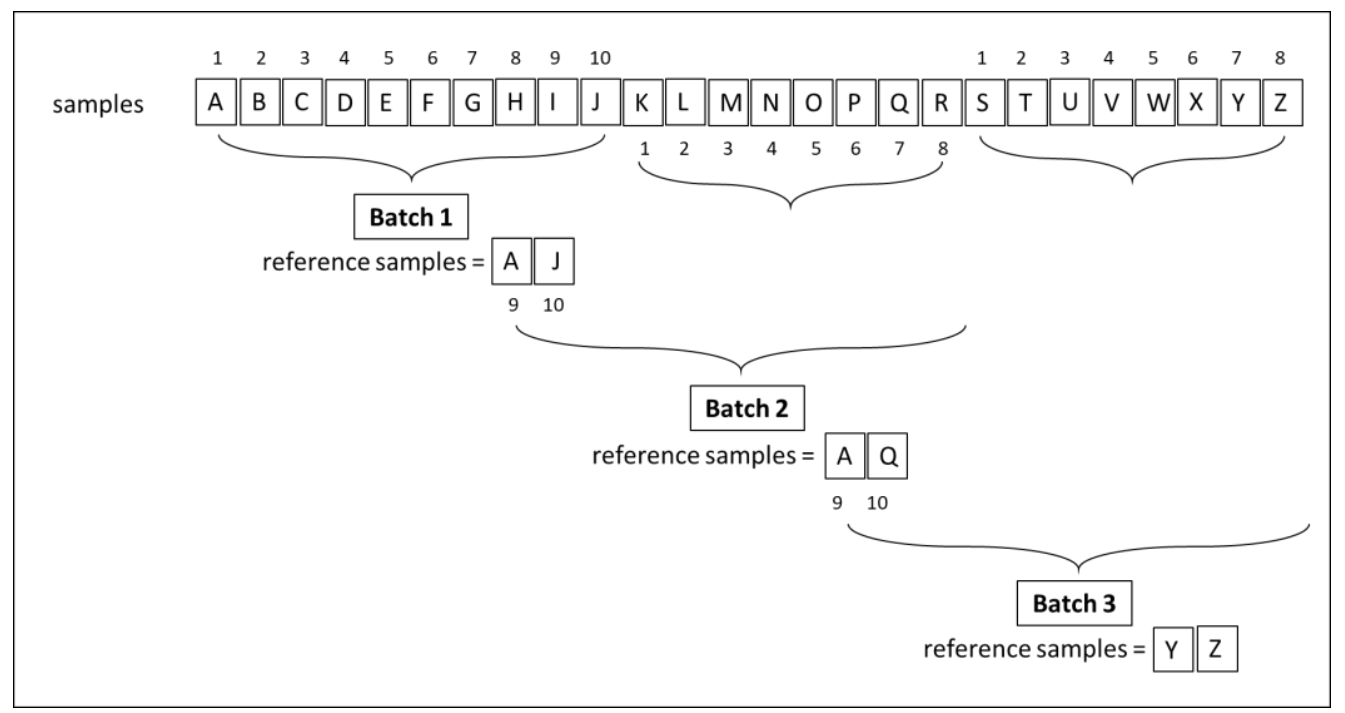

Figure 2 Example showing high number of samples i.e. 26 samples (A-Z) are split into batches of maximum 10 samples/batch for human measurement of fabric handle

\section{Analysis method}

Since the samples were fragmented in two assessment sessions, data normalization was applied to combine all the data on one new scale. The two reference samples from session 1 (i.e. knitted Tencel ${ }^{\circledR}$ and woven $\mu$ Modal ${ }^{\circledR}$ for warmth, knitted Tencel ${ }^{\circledR}$ and woven Modal $^{\circledR}$ for smoothness and knitted Tencel ${ }^{\circledR}$ and woven cotton for softness) were assessed in both sessions 1 and 2. We normalize on a scale of 1 to 9 as to bring the value of assessment as much as possible between 0 to 10 and to avoid as much as possible values $>10$. For each fabric attribute, the average value of the reference samples in session 1 is first determined. We call $\bar{x}_{\min }$ for the average of the reference sample with the lowest reading and $\bar{x}_{\max }$ is the one of the reference samples with the highest average. Thus we have $1 \leq \bar{x}_{\min } \leq \bar{x}_{\max } \leq 10$. In session 1 , the feature scaling is shown in Equation 2 where $x$ is the original value, $x^{\prime}$ is the normalized value, a and $b$ are the lowest and highest points in the new scale which are 1 and 9, respectively. For session 2, we obtain the average of the reference samples of session 1 and write them as $\bar{x}_{\min , 2}$ and $\bar{x}_{\max , 2}$. The normalized value of session 2 is calculated as shown in Equation 3. If a third session is needed, this approach can be continued as in Equation 4. Further statistical analysis was done on the results, first, a t-test and next, an analysis of variance (ANOVA) 
with $\mathrm{p}<0.05$. The results given by this method are compared with the relevant studies found in the literatures in which objective evaluation methods are used. This is to verify the findings and to confirm the feasibility of the newly discussed approach.

$x^{\prime}{ }_{i, 1}=a+\frac{\left(x_{i, 1}-\bar{x}_{\min , 1}\right)(b-a)}{\bar{x}_{\max , 1}-\bar{x}_{\min , 1}} ; i \in$ sample batch $1 ; \mathrm{a}=1 ; \mathrm{b}=9$

(Equation 2)

$x_{j, 2}^{\prime}=x_{\text {ref } \min , 1}^{\prime}+\frac{\left(x_{j, 2}-\bar{x}_{\min , 2}\right)\left(x_{\text {ref } \max , 1}^{\prime}-x_{\text {ref } \min , 1}^{\prime}\right)}{\bar{x}_{\max , 2}-\bar{x}_{\min , 2}} ; j \in$ sample batch 2

(Equation 3)

$x_{k, l}^{\prime}=x_{\text {ref min }, l-1}^{\prime}+\frac{\left(x_{k, l}-\bar{x}_{\text {min }, l}\right)\left(x^{\prime}{ }_{\text {ref max }, l-1}-x^{\prime}{ }_{\text {ref min }, l-1}\right)}{\bar{x}_{\text {max }, l}-\bar{x}_{\text {min }, l}} ; k \in$ sample batch $l$

(Equation 4)

\section{Results and discussion}

\section{Finger sensitivity}

The distribution of the panel members' age and origin with their finger sensitivity is presented in Figure 3, showing that 54\% panel members are from Europe and covers all age groups from 20 s to 50s. African panel members consist only $18 \%$ and the rest are Asians about 28\%. The panel members from Africa are around age of 30s while Asians are distributed from age 20 s to below 50 . We verified statistically that the finger sensitivity of the older panel members is lower than the young ones. Through the Pearson's correlation analysis $(\mathrm{p}=0.02)$, the relationship of age and the $g_{75}$ score gives $\mathrm{R}^{2}=0.32$. This means that the effect of the linear model is significant, but as $\mathrm{R}^{2}<0.5$ the variance is high and is not captured in the linear model based on age, which is to be expected. We can conclude that many factors must play a role in finger sensitivity, but nevertheless the reduction of sensitivity with age is significant.

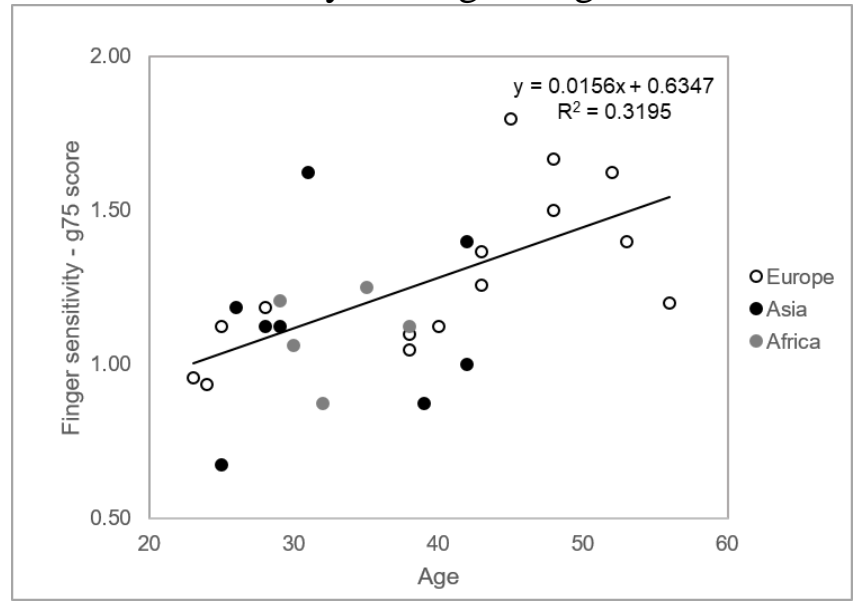

Figure 3 Distribution of age and origin versus finger sensitivity of the panel members

In Figure 4-left, the boxplots of age vs finger sensitivity show the variance of finger sensitivity for each age group. It seems that the distribution pattern can be further 
grouped into two groups, i.e. age 20-30 and age 40-50. ANOVA analysis confirms a significant difference between age groups denoted by $\mathrm{p}=0.001$, but the difference only lies for age 20s with 40s and 50s. For origin, the distribution pattern is almost similar for the three groups as shown in the boxplots (Figure 4-centre). A resulting $p=0.24$ shows no statistically significant difference between the sensitivity level of the three groups of origin. Same as origin, males and females also show no significant difference in their sensitivity for the selected group of panel members ( $\mathrm{p}=0.94)$ (Figure 4-right). As the panel members are the selected experts who fall within the range of sensitivity score, it is expected that their demographic aspects do not influence the sensitivity. Hence, the assessment results could not be affected by these factors.
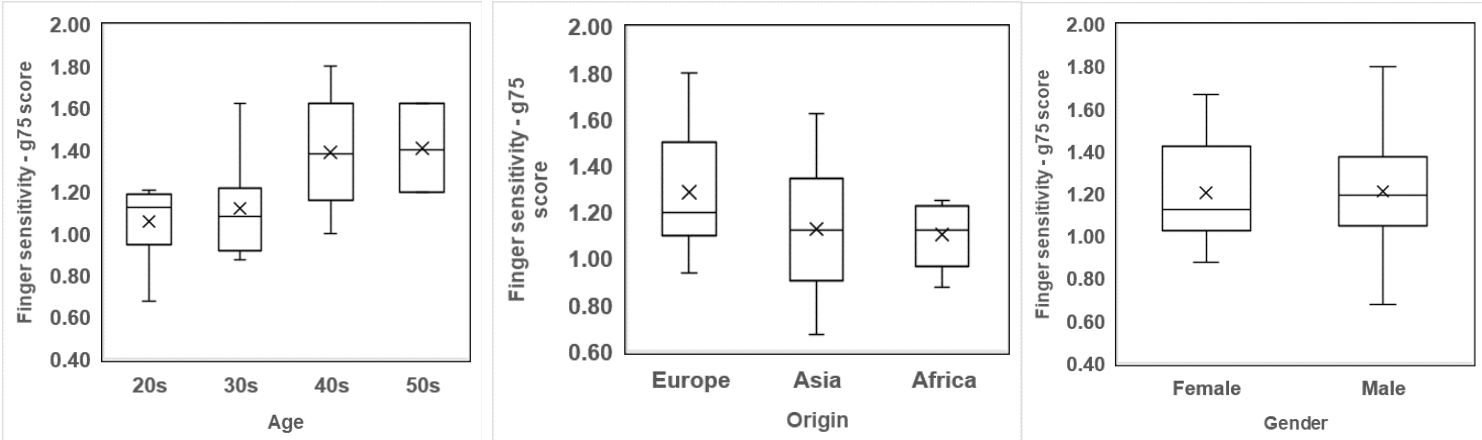

Figure 4 Boxplots showing the distribution of panel members' age groups (left), origin (center) and gender (right) vs finger sensitivity

\section{The blind rate experiment}

Prior to other analysis, Kendall's Coefficients of Concordance (W) was conducted to determine the consistency of the human assessment results ${ }^{38}$. First, the consistency for whole panel members in determining the three attributes and secondly, the performance of individual preference for the evaluated attributes. It is to note that this type of analysis is designed for rank data. So, first we have to convert the rates into rank to be able to implement the calculation, which based on the rating information is a straightforward conversion. Table 4 shows the results for the Kendall's W analysis for the whole panel members where $\mathrm{W}>0.5$ for all three attributes with highly significant results as $\mathrm{p}<0.05$. $\mathrm{W}$ values range from 0 to 1 . The coefficient value close to 1 indicates that the panel members performed consistent assessment amongst themselves. Hence for this data, we can conclude that the consistency of result from all panel members is good. For individual panel member, the concordance between the scores they assigned for softness, smoothness and warmth results were analyzed. We found no significant results $(\mathrm{W}<0.5$, $\mathrm{p}>0.05)$. This means no concordance was found, which proves that the panel members were evaluating different properties without being guided by an internal fitness of the fabrics not related to the property under investigation. 
Table 4 Kendall's consistency test result

\begin{tabular}{|l|l|l|l|}
\hline & Smoothness & Softness & Warmth \\
\hline Kendall's W & 0.68 & 0.89 & 0.56 \\
\hline$p$-value & $<0.001$ & $<0.001$ & $<0.001$ \\
\hline
\end{tabular}

The blind rate method was applied on the materials given in Section 2 - Materials. After normalization, the data from session 1 and 2 can be presented in one scale. The means and standard deviations (SD) of the samples for smoothness and softness are shown in Figure 5. Surface of woven and knitted fabrics is known to be different and the thickness of the fabrics also largely differs between the two groups (i.e., woven fabrics of $0.26-0.43$ $\mathrm{mm}$ and knitted fabrics of 0.51-0.64 mm). Hence smoothness and softness are separately discussed. Modal ${ }^{\circledR}$ fabric was selected as the smoothest and softest knitted fabric. Among the woven fabrics Modal ${ }^{\circledR} / \mu$ Modal $^{\circledR}$ and Tencel ${ }^{\circledR} / \mu$ Tencel $^{\circledR}$ are clearly smoother than the other fabrics. Wool and $\mu$ Tencel ${ }^{\circledR}$ were found the softest and the hardest woven fabric respectively. The objective measurement with devices such as FTT, TSA and Phabrometer ${ }^{\circledR}$ also indicates Modal ${ }^{\circledR}$-based fabrics as the smoothest and softest compared to other regenerated cellulose fabrics. ${ }^{39}$ Generally, the SD for softness is much lower than smoothness as illustrated by the error bars in the graphs. Nevertheless, the values (maximum SD is 3 for knitted Modal ${ }^{\circledR}$ - smoothness) can still be regarded as small which shows high agreements on the results between the panel members. In general, wood-based cellulosic fabrics especially Modal ${ }^{\circledR}$ give smoother and softer handle as shown by higher human scores compared to cotton. This is in line with the findings of previous research. ${ }^{39,40}$

In Figure 5-right, it can be clearly seen that the fabric construction i.e. woven-knitted, has impacted the softness result where knitted fabrics were generally perceived softer than the woven fabrics. A t-test analysis shows a significant difference between the two fabric constructions $(\mathrm{p}<0.001)$. Knitted fabrics are known for their bulkiness and airiness, and these would create a soft or fluffy feel when in contact with the skin. As in this case, thickness of knitted fabrics is higher than that of woven fabrics, hence we applied Pearson's correlation analysis which yield $R$-value $=0.74$ with $p=0.001$. This shows a good correlation between the thickness of the fabrics and softness attribute. Figure 5-left shows the smoothness results of the fabrics. The smoothness between knitted and woven fabrics is also significant different but only in case of cellulosic fabrics where woven cellulosic fabrics are significantly smoother $(\mathrm{p}=0.006)$ than knitted fabrics of same composition. On contrary, non-cellulosic woven fabrics are even rougher than knitted fabrics. These may be attributed to different yarn linear density used for each fabric construction. As finer yarns will lead to smoother fabrics ${ }^{2,41}$, thus we can see that cellulosic fabrics which were constructed with finer yarns (i.e. 10 Tex for woven fabrics and 20 Tex for knitted fabrics) and non-cellulosic woven fabrics made from yarns of 3040 Tex have different smoothness and roughness feel. A very good correlation with $\mathrm{R}=0.84(\mathrm{p}<0.001)$ was observed between warp yarn linear density and smoothness attribute. 
The fabrics of this dataset greatly differ in terms of fabric composition, weave structure and fabric density therefore, based on this dataset of 13 fabrics, we cannot conclude which of these parameters led to the change of fabric hand and this is also beyond the scope of the paper. A Design of Experiment (DoE) could be employed for that purpose, which is a method for systematically planning and conducting experiments by making controlled changes to input variables in order to determine their effect on a given response. It requires a limited number of experiments (combination of input variables) for a maximum amount of information about the responses ${ }^{42}$.
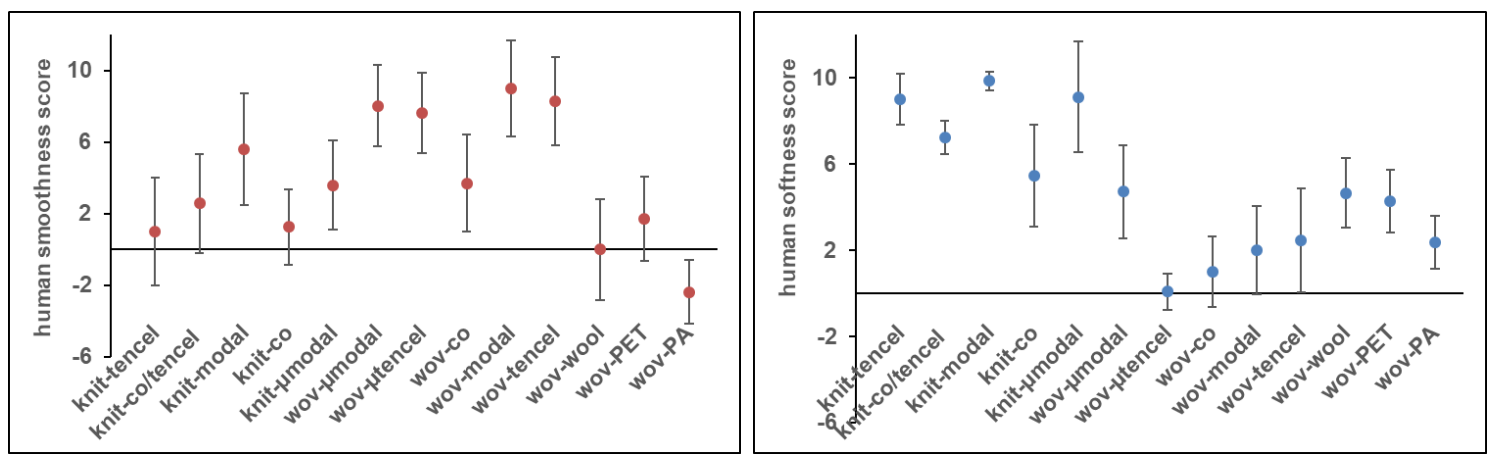

Figure 5 Mean scores for smoothness (left) and softness (right) with error bars showing standard deviation (SD)

Figure 6-left shows the mean scores for warmth human evaluation given to all fabrics. It seems that woven and knitted fabrics can be segregated based on this attribute. Modal ${ }^{\circledR}$ fabric was chosen as the warmest for knitted and polyester for woven, while the coolest for knitted is cotton/Tencel ${ }^{\circledR}$ and $\mu$ Tencel ${ }^{\circledR}$ for woven. Large discrepancies were observed among the panel members which is shown by the error bars. Warmth is measured during the initial contact of the skin onto the fabric and it was evaluated prior the other two attributes. However, the panel members have high disagreement on warmth attribute, which might be due to the small differences on the thermal sensation that the panels were not able to discern. The disagreement among panels was also discussed by previous researchers who also pointed out the same issue on the assessment of warmth. ${ }^{20,43}$ Nevertheless, we can still see that the panel members were able to depict the warmth sensation in two groups of knitted and woven fabrics, where knitted fabric were assessed as significantly warmer as compared to woven fabrics ${ }^{10}$, see Figure 6-right. This is confirmed by a t-test statistical method where $\mathrm{p}<0.001$. As we look at thickness of the materials, knitted fabrics are thicker than woven fabrics. To some extent, thickness can change the thermal-contact feeling of the tested fabrics which makes thicker fabrics feel warmer ${ }^{34}$. A good correlation was found between thickness and warmth with $\mathrm{R}=0.80$, $\mathrm{p}<0.001$. The panel members also indicated that knitted fabrics are rougher than woven cellulosic fabrics. Rougher fabrics have smaller contact interfacial area and more air is entrapped on fabric surface, thus these fabrics gives warmer feeling ${ }^{44}$ and on the other hand smoother surfaces are perceived as cooler ${ }^{45,46}$. 

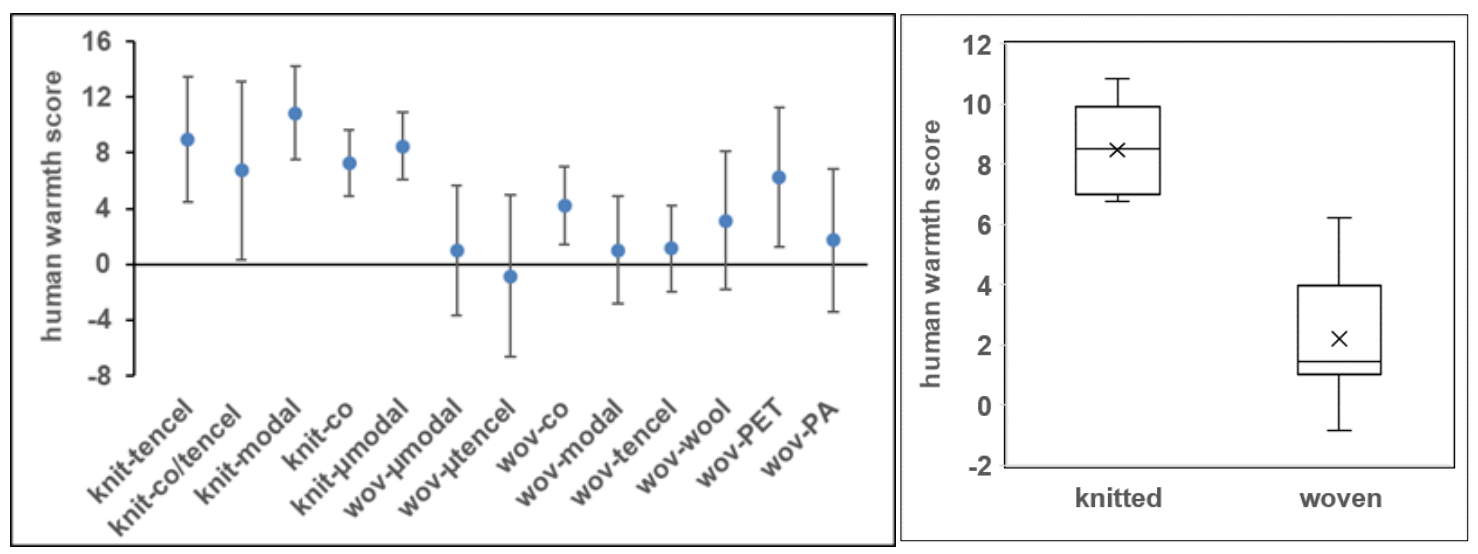

Figure 6 Left - mean scores for warmth with error bars showing standard deviation (SD), right -boxplot showing the distribution of human warmth assessment score for knitted and woven fabrics

Since the panel members consist of experienced and inexperienced persons, an ANOVA test was run (significance level alpha $=0.05$ ) to identify possible significant differences between the two groups. No significant differences between the two groups were found, probably due to their common background in textiles that makes them familiar with fieldspecific definitions, terms and testing procedures. Hence, their judgement on the fabric handles was similar. However, the results could have been different if the panels were novices or untrained consumers. ${ }^{3}$

The panel have age varying from 20 s to 50 s, therefore we analyzed the data to study the differences in assessing the fabrics attributed to age difference. The 28 panel members are grouped by their age where 9 panel members are in age 20s, 8 are 30s, 8 also for 40s and 3 of age 50s. An ANOVA test (alpha=0.05) was applied and the null hypothesis $\left(\mathrm{H}_{0}\right)$ was accepted in all cases, meaning that the impact of age on assessment is not statistically significant except smoothness of three fabrics i.e. knitted Tencel ${ }^{\circledR}$, woven cotton and Modal ${ }^{\circledR}$ fabrics (Table 5). It seems that older people find the knitted Tencel ${ }^{\circledR}$ fabric smoother than the younger ones and vice-versa for woven cotton and Modal ${ }^{\circledR}$ as presented in Figure 7. As mentioned earlier in the previous section, age of the panel members can be grouped into two i.e. 20s-30s and 40s-50s, based on their finger sensitivity. Hence, we analyze the smoothness results of these three fabrics based on the two groups. It is found that only woven cotton fabrics have significant difference between the two groups of age. Nevertheless, this single exception out of all other cases should not be given too much weight as it could randomly appear through the statistics, as we might find also if we test nonsensical parameters such as height or weight of the panel members vs their subjective judgement.

Spatial acuity of touch depreciates noticeably by age as reported by many researchers. ${ }^{47-}$ ${ }^{49}$ As we grow older, our sensitivity reduced, likewise for the touch perception on the fabrics. However, this factor could be different for each individual as in our case. As mentioned earlier, the panel members in this study were carefully selected having good range of skin sensitivity after being screened with JVP Domes. Hence, it is expected that 
the panel members' age would not give much influence to the touch, for this particular study.

Table 5 Results for ANOVA analysis showing $p$-values where $p<0.05$ indicates the rejection of $\mathrm{H}_{0}$ hypothesis $\left(\mathrm{H}_{0}=\right.$ assumes the means of the samples are the same among the groups studied)

\begin{tabular}{|l|l|l|l|l|l|l|}
\hline \multirow{2}{*}{ Fabric ID } & \multicolumn{2}{l}{$\begin{array}{l}\text { p-value for age groups - 20s, 30s, 40s, } \\
50 \mathrm{l}\end{array}$} & \multicolumn{2}{l}{$\begin{array}{l}\text { p-value for origin - Europe, Asia, } \\
\text { Africa }\end{array}$} \\
\cline { 2 - 7 } & Smoothness & Softness & Warmth & Smoothness & Softness & Warmth \\
\hline knit-tencel & $0.02^{*}$ & 0.22 & 0.36 & 0.18 & 0.17 & $0.01^{*}$ \\
\hline $\begin{array}{l}\text { knit- } \\
\text { co/tencel }\end{array}$ & 0.79 & 0.71 & 0.46 & 0.85 & 0.15 & 0.86 \\
\hline knit-modal & 0.06 & 0.94 & 0.69 & $0.02^{*}$ & 0.16 & 0.95 \\
\hline knit-co & 0.28 & 0.86 & 0.53 & 0.66 & 0.93 & 0.10 \\
\hline knit- $\mu$ modal & 0.50 & 0.70 & 0.14 & 0.20 & 0.41 & 0.12 \\
\hline wov- $\mu$ modal & 0.47 & 0.36 & 0.86 & 0.87 & 0.28 & 0.92 \\
\hline wov- $\mu$ tencel & 0.10 & 0.64 & 0.49 & 0.49 & 0.55 & $0.01^{*}$ \\
\hline wov-co & $0.00^{*}$ & 0.27 & 0.84 & 0.15 & 0.08 & 0.78 \\
\hline wov-modal & $0.00^{*}$ & 0.60 & 0.68 & 0.10 & 0.17 & 0.06 \\
\hline wov-tencel & 0.08 & 0.95 & 0.78 & 0.73 & 0.97 & 0.16 \\
\hline wov-wool & 0.51 & 0.20 & 0.30 & 0.70 & 0.67 & 0.60 \\
\hline wov-PET & 0.69 & 0.11 & 0.56 & 0.57 & 0.33 & 0.97 \\
\hline wov-PA & 0.63 & 0.67 & 0.24 & 0.95 & 0.26 & 0.38 \\
\hline
\end{tabular}

*significant difference between sample, p-value $<0.05$ 

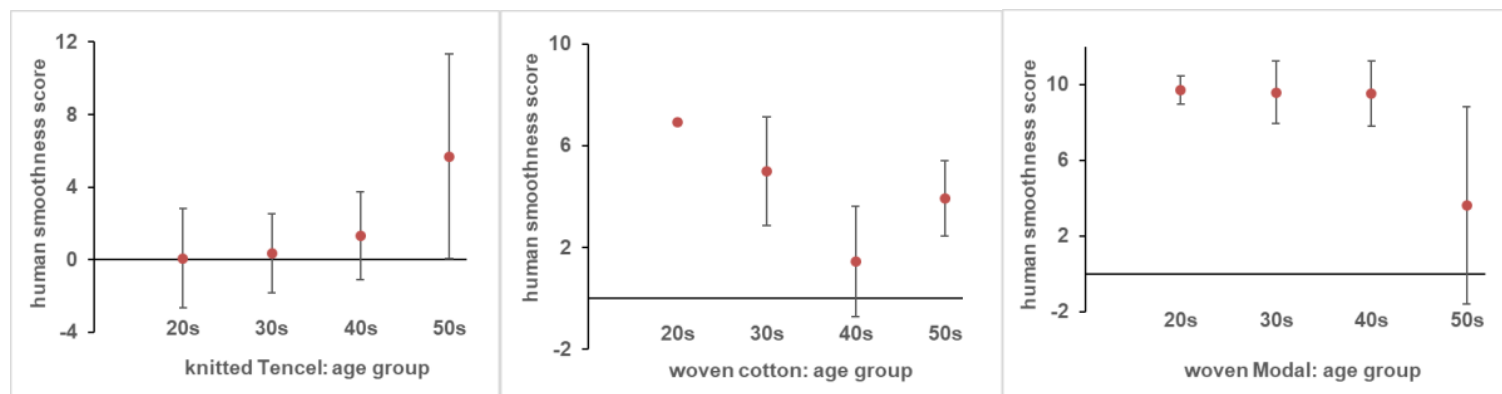

Figure 7 Mean scores for smoothness vs age of the panel members for knitted Tencel ${ }^{\circledR}$ (left), woven cotton (middle) and woven Modal ${ }^{\circledR}$ (right)

An ANOVA analysis was applied on the data obtained from panel consisting of 15 Europeans, 8 Asians and 5 Africans to identify assessment differences due to origin. Similarly, we found that the origin of the panel members does not influence their judgement of fabrics handle with exception of three cases i.e. smoothness for knitted Modal $^{\circledR}$, and warmth for knitted Tencel ${ }^{\circledR}$ and woven $\mu$ Tencel ${ }^{\circledR}$ (p-value $<0.05$ as tabulated in Table 5). The graphs in Figure 8 show that Africans feel the knitted Tencel ${ }^{\circledR}$ fabric as cooler but warmer for woven $\mu$ Tencel ${ }^{\circledR}$ compared to Europeans and Asians. For knitted Modal ${ }^{\circledR}$ fabric, Asians found it rougher followed by Europeans, and Africans found it as the warmest. Again, these exceptions are minor cases which should not be given much emphasis. The results of finger sensitivity showed no significant differences between the panel members due to their origins, as reported earlier in the previous sub-section. Similarly, we found no significant differences between the fabric handle assessment of males and females panel members ( $>>0.05)$. Since we already screened the finger sensitivity of the panel members and retained only those within a certain range, it seems that the disagreements between the panel members due to demographic criteria i.e. age, gender, origin can be overruled. We also analyze the relationship between the finger sensitivity and subjective assessment score. The results show no correlation for all three attributes.

Although through some previous researches, it is found that there are apparently culturally based differences in handle assessment, those are mainly for preferences on good hand fabric. For instance, Japanese panel members prefer stiffer fabrics, in contrast with Australian, New Zealand and Indians who preferred a relatively lower stiffness for a lightweight summer materials. ${ }^{30,50}$
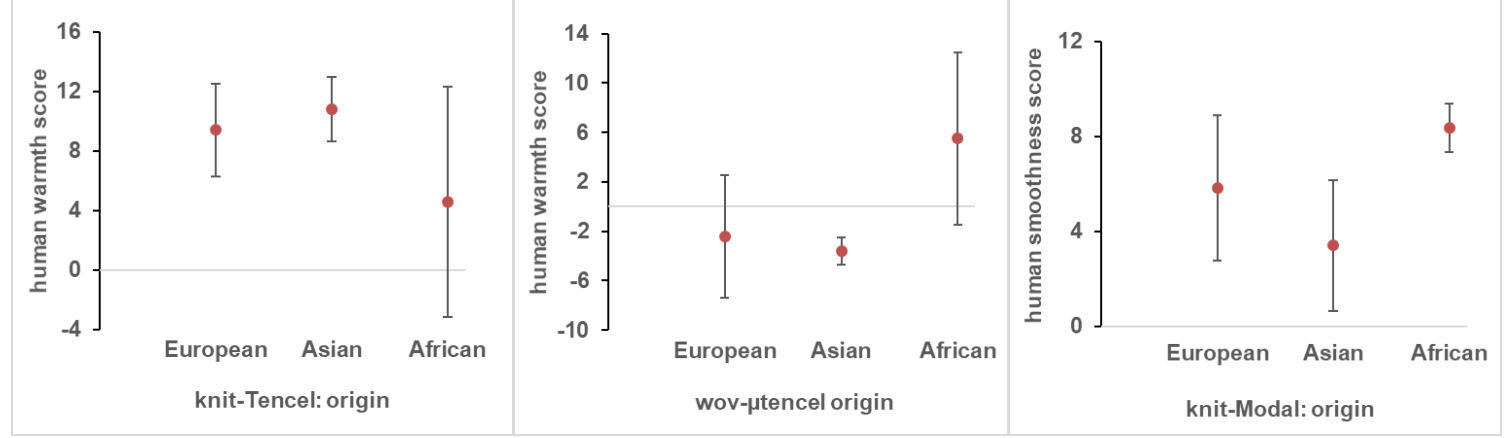

Figure 8 Warmth scores vs origin of the panel members for knitted Tencel ${ }^{\circledR}($ left), woven $\mu$ Tencel $^{\circledR}$ (middle) and smoothness scores vs origin for knitted Modal ${ }^{\circledR}$ (right) 


\section{Conclusion}

Fabric hand assessment prominently relies on the feel of humans. Generally, the size of fabric sets impacts the precision of the results where it decreases with increasing number of samples. This is due to the human factors in which they are prone to fatigue and loss of focus when assessing a large sample sets, in addition to a long testing duration. Considering the importance of handle assessment and the lack of guidelines that assist assessment of large sample sets, this study suggests a method to test a large set of fabrics in which the samples are split in several sessions, with 10 samples at most for each session. To overcome possible disagreements between the panel members as results of their different age, gender and origin, a selection method is proposed based on their finger sensitivity. The method to select the panel members, link the results obtained in different sessions and normalize the data are discussed in this paper.

The proposed method was implemented on 13 fabrics from a typical range of apparel clothing fabrics. Three fabric sensorial attributes (i.e. smoothness, softness and warmth) were assessed in two sessions by a panel consisting of 28 blindfolded members. Good agreement was found between the panel members for fabric smoothness and softness. However, the panel judged the warmth of the fabrics differently, probably due to small, difficult to discriminate differences between the samples and their personal preferences. Nevertheless, the panels clearly differentiated knitted and woven fabrics according to their warmth.

We found no significant differences between the assessments due to gender, origin or age-based difference. That can be attributed to the background in textiles engineering of all panel members and their selection criteria was based on similar finger sensitivity. The findings of this study are in agreement with previous studies where well-established assessment methods were applied and suggest that the proposed method can be applied to assess large sets of fabrics. As a limitation, the fabrics shall have comparable thickness, weight, texture etc. Otherwise, the rating scale of 1 to 10 would be too limited to grasp the full range of fabrics. In other words, the reference samples should not grow too distinct.

Through the present technique using split sample batches, large-size set of fabrics can be assessed without jeopardizing the focus of the panels. This triggers future possibilities for inter-laboratory assessment after selecting the reference fabrics to be used across institutions. By this means, diversified type of fabrics can be evaluated by larger panels located worldwide, thus the results will be more meaningful.

\section{References}

1. Dawes VH, Owen JD. The assessment of fabric handle, Part I: stiffness and liveliness. J Text Inst 1971; 62: 233-244.

2. Kayseri GÖ, Özdil N, Mengüç GS. Sensorial comfort of textile materials. Woven Fabr 2012; 235-266.

3. Bishop DP. Fabrics: sensory and mechanical properties. Text Prog 1996; 26: 1-62. 
4. American Association of Textile Chemists and Colorists. AATCC evaluation procedure 5-2011, AATCC technical manual. Research Triangle Park, North Carolina: American Association of Textile Chemists and Colorists, 2014.

5. Ciesielska-Wrobel IL, Van Langenhove L. The hand of textiles - definitions, achievements, perspectives - a review. Text Res J 2012; 82: 1457-1468.

6. Binns H. The Discrimination of Wool Fabrics By the Sense of Touch. Br J Psychol Gen Sect 1926; 16: 237-247.

7. Kawabata S, Niwa M. Fabric performance in clothing and clothing manufacture. $J$ Text Inst 1989; 80: 19-50.

8. De Boos A, Tester D. SiroFAST-a system for fabric objective measurement and its application in fabric. Canberra, 1994.

9. Liao X, Li Y, Hu J, et al. A simultaneous measurement method to characterize touch properties of textile materials. Fibers Polym 2014; 15: 1548-1559.

10. Hu JY, Hes L, Li Y, et al. Fabric touch tester: integrated evaluation of thermalmechanical sensory properties of polymeric materials. Polym Test 2006; 25: 10811090.

11. Yao BG, Peng YL, Yang YJ. Mechanical measurement system and precision analysis for tactile property evaluation of porous polymeric materials. Polymers (Basel) 2018; 10: 1-18.

12. Strazdiene E, Gutauskas M. New method for the objective evaluation of textile hand. Fibres Text East Eur 2005; 13: 35-38.

13. Kim JO, Slaten BL. Objective evaluation of fabric hand, Part I: relationships of fabric hand by the extraction method and related physical and surface properties. Text Res J 1999; 69: 59-67.

14. Sular V, Okur A. Objective Evaluation of Fabric Handle by Simple Measurement Methods. Text Res J 2008; 78: 856-868.

15. Hes L, Dolezal I. New method thermal and equipment for measuring properties of textiles. Sen 'i Kikai Gakkaishi (Journal Text Mach Soc Japan), 1989; 42: 71-75.

16. Osgood CE, Suci GJ, Tanne PH. The measurement of meaning. Illinois, USA: University of Illinois Press, 1957.

17. Slater K. Subjective textile testing. J Text Inst 1997; 88: 79-91.

18. Ellis BC, Garnsworthy RK. Techniques for the assessment of hand. Text Res $J$ 1980; 231-238.

19. Grinevičiūte D, Gutauskas M. The Comparison of Methods for The Evaluation of Woven Fabric Hand. 2004; 10: 97-100.

20. Vasile S, Malengier B, Deruyck F, et al. Influence of selected production parameters on the hand of mattress knitted fabrics assessed by the Fabric Touch Tester. Text Res $J$.

21. C. Meilgaard M, Vance Civille G, Thomas Carr B. Sensory evaluation techniques. Fourth Edi. New York: CRC Press, 2007.

22. Stoelting Company. Operation manual: J.V.P.* Domes, for cutaneous spatial resolution measurement. Wood Dale, Illinois, 1997.

23. Bleyenheuft Y, Thonnard JL. Tactile spatial resolution measured manually: A validation study. Somatosens Mot Res 2007; 24: 111-114.

24. Remblay F, Backman a, Cuenco a, et al. Assessment of spatial acuity at the fingertip with grating (JVP) domes: validity for use in an elderly population. 
Somatosens Mot Res 2000; 17: 61-66.

25. Zangaladze A. Sathian, MD, PhD, and A. Zangaladze, MD, PhD Gratings, consisting of alternating ridges and. Neurology 1996; 1995-1997.

26. Sathian K, Zangaladze A, Green J, et al. Tactile spatial acuity and roughness discrimination: Impairments due to aging and Parkinson's disease. Neurology 1997; 49: 168-177.

27. Van Boven RW, Johnson KO. The Limit of Tactile Spacial Resolution in Humans. Neurology 1994; 44: 1074-1078.

28. ASTM International. D1776-04: Standard practice for conditioning and testing textiles. 2004; $1-4$.

29. Mooneghi SA, Saharkhiz S, Varkiani SMH. Surface Roughness Evaluation of Textile Fabrics: A Literature Review. J Eng Fiber Fabr 2014; 9: 1-18.

30. De Boos A, Tester D. SiroFast - fabric assurance by simple testing. In: M.Behery $\mathrm{H}$ (ed) Effect of mechanical and physical properties on fabric hand. Cambridge, England: woodhead publishing limited, 2005, pp. 443-463.

31. ASTM International. ASTM D123-17: Standard terminology relating to textiles. 2013; $1-68$.

32. Liao X, Li Y, Hu J, et al. Effects of contact method and acclimation on temperature and humidity in touch perception. Text Res $J$ 2017; 004051751770562.

33. Sular V, Okur A. Sensory evaluation method for tactile properties of fabrics. $J$ Sens Stud 2007; 22: 1-16.

34. Hes L, Offerman P, Dvorakova I. The effect of underwear on thermal contact feeling caused by dressing up and wearing of garments. In: Proceedings of Tecnitex 2001 Autex Conference, 2001. 2001, pp. 236-245.

35. Bacci L, Camilli F, Drago S, et al. Sensory evaluation and instrumental measurements to determine tactile properties of wool fabrics. Text Res $J$ 2012; 82: 1430-1441.

36. Pensé-Lhéritier AM, Guilabert C, Bueno MA, et al. Sensory evaluation of the touch of a great number of fabrics. Food Qual Prefer 2006; 17: 482-488.

37. Kandzhikova GD, Germanova-Krasteva DS. Subjective evaluation of terry fabrics handle. J Text Inst 2016; 107: 355-363.

38. Kendall MG. Rank correlation methods. Fourth edi. Charles Griffin \& Company Limited London, 1970.

39. Abu-Rous M, Malengier B, Liftinger E, et al. Handfeel of single jersey fabrics as assessed by a new physical method. J Fash Technol Text Eng 2018; s4: 4-8.

40. Abu-Rous M, Liftinger E, Innerlohinger J, et al. A new physical method to assess handle properties of fabrics made from wood-based fibers. IOP Conf Ser Mater Sci Eng; 254. Epub ahead of print 2017. DOI: 10.1088/1757-899X/254/14/142001.

41. Luible PC. Study of Mechanical Properties in the Simulation of 3D Garments. University of Geneva, 2008.

42. Antony J. Design of Experiments for Engineers and Scientists. Oxford, UK: Elsevier Science \& Technology Books, 2003.

43. Niedermann R, Rossi RM. Objective and subjective evaluation of the human thermal sensation of wet fabrics. Text Res J 2012; 82: 374-384.

44. Pac MJ, Bueno MA, Renner M, et al. Warm-cool feeling relative to tribological 
properties of fabrics. Text Res $J$ 2001; 71: 806-812.

45. Vasile S, Malengier B, De Raeve A, et al. FTT comfort indices of ring spun and air-jet knitted fabrics with post-treatments. In: Autex Conference Proceeding. Corfu, Greece, 2017.

46. Vivekanadana M V., Raj S, Suffixeenivasan S, et al. Parameters affecting warmcool feeling in cotton denim fabrics. Indian J Fibre Text Res 2011; 36: 117-121.

47. Gerhardt LC, Lenz A, Spencer ND, et al. Skin-textile friction and skin elasticity in young and aged persons. Ski Res Technol 2009; 15: 288-298.

48. Wickremaratchi MM, Llewelyn JG. Effects of ageing on touch. Postgrad Med J 2006; 82: 301-304.

49. Zhu YH, Song SP, Luo W, et al. Characterization of skin friction coefficient, and relationship to stratum corneum hydration in a normal Chinese population. Skin Pharmacol Physiol 2011; 24: 81-86.

50. Dhingra RC, Liu D, Postle R. Measuring and interpreting low-stress fabric mechanical and surface properties: Part II: application to finishing, drycleaning, and photodegradation of wool fabrics. Text Res J 1989; 59: 357-368. 